Open Access

\title{
Differences in pregnancy outcomes and characteristics between insulin- and diet- treated women with gestational diabetes
}

Katrien Benhalima ${ }^{*}$, Karolien Robyns ${ }^{1}$, Paul Van Crombrugge ${ }^{2}$, Natascha Deprez ${ }^{2}$, Bruno Seynhave ${ }^{3}$, Roland Devlieger ${ }^{4}$, Johan Verhaeghe ${ }^{4}$, Chantal Mathieu ${ }^{1}$ and Frank Nobels ${ }^{2}$

\begin{abstract}
Background: Our aim was to evaluate the difference in pregnancy outcomes and characteristics between insulin- and diet-treated women with gestational diabetes (GDM).

Methods: Retrospective analysis of the medical files from 2010-2013 of women with GDM diagnosed with the Carpenter \& Coustan criteria attending two clinics, one in a university and another in a non-university hospital. Characteristics associated with insulin use were analyzed. Multivariable logistic regression was used to adjust for confounders. For women attending the university hospital, indices of insulin sensitivity such as the reciprocal of the homeostasis model assessment of insulin resistance (1/HOMA-IR) and an index of beta-cell function, the Insulin Secretion-Sensitivity Index-2 (ISSI-2) were calculated.

Results: Over a 4 year period, 601 women were identified with GDM of whom $22.9 \%$ were obese at first prenatal visit. $24.2 \%$ needed insulin. Insulin did not prevent adverse outcomes, as women on insulin had higher rates of large-forgestational age infants (LGA) ( $28.5 \%$ vs. $13.1 \%, p<0.0001)$ and more cesarean sections ( $44.1 \%$ vs. $27.0 \%, p=0.001)$, remaining significant after adjustment for confounders. Compared to diet-treated women, women on insulin more often had an ethnic minority background (33.3\% vs. $21.6 \%, p=0.004)$, more often had a history of GDM (21.5 \% vs. $10.4 \%$, $p=0.002)$, were more often multiparous ( $59.3 \%$ vs. $47.6 \%, p=0.044$ ) and were diagnosed with GDM earlier in pregnancy (weeks $25.3 \pm 4.9$ vs. $27.1 \pm 3.7, p<0.0001$ ). When undergoing an oral glucose tolerance test, women treated with insulin had a higher fasting glycaemia ( $97.6 \pm 18.8$ vs.87.7 $\pm 10.3, p<0.0001)$, a higher 1-hour glycaemia (197.7 \pm 30.1 vs.184.5 \pm $25.8, p<0.0001$ ), a higher 2-hour glycaemia (185.2 \pm 28.5 vs. $175.0 \pm 22.8, p<0.0001$ ), more often 3 and 4 abnormal values ( $58.1 \%$ vs. $37.8 \%, p<0.0001$ and $24.8 \%$ vs. $7.7 \%, p<0.0001$ ) and higher HbA1c levels (5.5 \pm 0.6 vs $5.2 \pm 0.5, p<0.0001$ ). ISSI-2 (1.3 \pm 0.5 vs. $1.7 \pm 0.5, p<0.0001)$ and $1 / \mathrm{HOMA}-\mathrm{IR}[0.01(0.001-0.002)$ vs. $0.02(0.01-0.03), p=0.027]$ were lower in women on insulin. Women on insulin more often received corticoids in preparation of preterm delivery (11.0\% vs. $2.4 \%$, $p<0.0001)$.

Conclusion: Compared to diet-treated women with GDM, women treated with insulin have a higher risk profile, impaired beta-cell function and lower insulin sensitivity. Rates of LGA and cesarean sections were higher in insulin-treated women.
\end{abstract}

Keywords: Gestational diabetes, Treatment, Insulin, Diet

\footnotetext{
* Correspondence: katrien.benhalima@uzleuven.be

'Department of Endocrinology, UZ Gasthuisberg, KU Leuven, Herestraat 49,

3000 Leuven, Belgium

Full list of author information is available at the end of the article
}

C Biomed Central

(C) 2015 Benhalima et al. Open Access This article is distributed under the terms of the Creative Commons Attribution 4.0 International License (http://creativecommons.org/licenses/by/4.0/), which permits unrestricted use, distribution, and reproduction in any medium, provided you give appropriate credit to the original author(s) and the source, provide a link to the Creative Commons license, and indicate if changes were made. The Creative Commons Public Domain Dedication waiver (http://creativecommons.org/publicdomain/zero/1.0/) applies to the data made available in this article, unless otherwise stated. 


\section{Background}

Gestational diabetes (GDM) is a frequent medical condition during pregnancy and was historically defined as 'any degree of glucose intolerance with onset or first recognition during pregnancy' [1]. GDM has long been known to raise the risk of a large-for-gestational age infant (LGA) and macrosomia resulting in increased rates of shoulder dystocia and caesarian deliveries [2, 3]. Shortly after the delivery the glucose values are generally restored to normal, but women with GDM have a sevenfold increased risk of developing type 2 diabetes (T2DM) [4]. Two large randomized intervention trials have demonstrated improvement in perinatal outcomes in the group of women who received treatment of mild GDM, especially in the frequency of LGA and preeclampsia $[5,6]$. Initial treatment of GDM involves diet modification, glucose monitoring and moderate exercise [7]. If lifestyle is insufficient to maintain the glycemic targets, pharmacological therapy becomes necessary. Insulin has been the treatment of choice when lifestyle measures do not maintain glycemic control during pregnancy. Recent studies have suggested that metformin and glibenclamide (glyburide) may be safe and acceptable alternatives but there is a paucity of long-term follow up data on children exposed to oral agents in utero $[8,9]$. Recent data also point towards the fact that sulfonylurea do cross the placenta when used in high doses [10]. The American Diabetes Association (ADA) therefore only recommends insulin as pharmacotherapy for GDM [7]. The difference in pregnancy outcomes between insulin- and diet-treated women with GDM and the profile of women where insulin-therapy is warranted, remain unclear. The aim of our study was therefore to evaluate the pregnancy outcomes and characteristics in insulin- versus diet-treated women with GDM in Belgian patients.

\section{Methods}

Retrospective analysis of the electronic medical files of all women with GDM diagnosed with the Carpenter \& Coustan criteria attending two large obstetrical centers in Belgium (the University Hospital UZ Leuven and the non-university hospital OLV Aalst-AsseNinove) from 01-01-2010 till 31-12-2013. The study was approved by the Institutional Review Board of UZ Leuven (ML 10085) and by the Institutional Review Board of the hospital OLV Aalst-Asse-Ninove (B126201422577). Due to the retrospective nature of the study there was no need for informed consent from the participants as in compliance with the Belgian Law of December 8,1992 on the protection of privacy and the Belgian Law of August 22, 2002 on the rights of the patient.
Approximately 2400 women are delivered annually at UZ Leuven and about 1700 women at the hospital OLV Aalst-Asse-Ninove. The background prevalence of T2DM in the adult Belgian population is $6.5 \%$ [11]. In the general adult population $28 \%$ of women are overweight and $13 \%$ are obese [12]. Accurate data on the prevalence of GDM are lacking in Belgium and the current practice for screening for GDM varies across different centers [13]. In both centers, women were not yet universally screened for overt diabetes early in pregnancy. All pregnant women were screened and diagnosed for GDM according to the Fifth International Workshop Conference criteria [14]. Women received a 50 g glucose challenge test (GCT) between 24-28 weeks and those testing positive [threshold after $1-\mathrm{h} \geq 140 \mathrm{mg}$ / $\mathrm{dl}(7.8 \mathrm{mmol} / \mathrm{l})]$ had a 3-hour $100 \mathrm{~g}$ oral glucose tolerance test (OGTT) within two weeks after the GCT using the Carpenter \& Coustan criteria for GDM [fasting plasma glucose (FPG) $\geq 95 \mathrm{mg} / \mathrm{dl}(5.3 \mathrm{mmol} / \mathrm{l})$, 1-hour glycaemia $\geq 180 \mathrm{mg} / \mathrm{dl} \quad(10.0 \mathrm{mmol} / \mathrm{l}), 2$-hour glycaemia $\geq 155 \mathrm{mg} / \mathrm{dl}(8.6 \mathrm{mmol} / \mathrm{l})$ and 3-hour glycaemia $\geq 140 \mathrm{mg} / \mathrm{dl}(7.8 \mathrm{mmol} / \mathrm{l})$, diagnosis of GDM if $\geq 2$ values are abnormal]. Although there are no specific recommendations in both centers on which women should receive screening for GDM before 24 weeks of pregnancy, screening for GDM with a $50 \mathrm{~g} \mathrm{GCT} \mathrm{is} \mathrm{sometimes} \mathrm{performed} \mathrm{before} 24$ weeks of pregnancy in high risk women such as women with a history of GDM. Women with GDM were treated with insulin when despite lifestyle measures the FPG was $\geq 95 \mathrm{mg} / \mathrm{dl}(5.3 \mathrm{mmol} / \mathrm{l})$ and/or 2-hour postprandial glycaemia $\geq 120 \mathrm{mg} / \mathrm{dl}(6.7 \mathrm{mmol} / \mathrm{l})$. To uniform the initiation for insulin therapy as much as possible, the 'Weekly Average Glycaemia' (WAG) is calculated based on the self-monitoring values of the blood glucose (fasting and postprandial) during the first weeks after the diagnosis. Therapy with insulin is initiated when the fasting WAG and/or the postprandial WAG is above target during two weeks in a row. The treatment and follow up policies were identical in both centers. In both centers oral anti-diabetes drugs such as metformin and glibenclamide (glyburide) are not routinely used during pregnancy.

Outcomes were obtained from review of the electronic database. Maternal characteristics recorded were age, ethnicity, weight, body mass index (BMI) at first prenatal visit and at delivery, overweight (BMI $\geq 25 \mathrm{Kg} / \mathrm{m}^{2}$ ), obesity (BMI $\geq 30 \mathrm{Kg} / \mathrm{m}^{2}$ ), weight gain (difference in weight between first prenatal visit and the delivery), parity, a history of a first degree or second degree relative with diabetes and history of GDM. Excessive weight gain was defined according to the most recent Institute of Medicine (IOM) guidelines [15]. Other data that were recorded are: the glucose values and the insulin values 
(only for UZ Leuven) based on the $100 \mathrm{~g}$ OGTT during pregnancy (0 min-60 min-120 min-180 min), gestational age at delivery, the timing and result of the GCT, the gestational age at the diagnosis of GDM, HbA1c at the time of the $100 \mathrm{~g}$ OGTT during pregnancy, whether women received treatment with corticoids during pregnancy, need of insulin, type of insulin and number of injections and the gestational age at the start of insulin.

The following maternal pregnancy outcomes were recorded: gestational hypertension (blood pressure $\geq 140$ / $90 \mathrm{mmHg}$ ), preeclampsia [hypertension with proteinuria or in combination with reduced fetal growth or the 'Hemolysis Elevated Liver enzymes and Low Platelets' (HELPP)-syndrome], preterm delivery ( $<37$ weeks of gestation) and cesarean section (planned + emergency sections combined). The following neonatal outcomes were recorded: birth weight, macrosomia (birth weight > $4 \mathrm{~kg}$ ), large-for-gestational age infants (LGA, birth weight $>90$ percentile adjusted for sex and parity), smallfor-gestational age infants (SGA, birth weight $<10$ percentile adjusted for sex and parity), shoulder dystocia, Apgar score (at five minutes) and admission at the neonatal intensive care unit (NICU).

Since insulin levels were not available from women from the OLV Aalst-Asse-Ninove hospital, indices of insulin sensitivity and an index of beta-cell function were only analyzed from women attending the university hospital UZ Leuven. Insulin sensitivity was measured using the insulin sensitivity index of Matsuda, a wellestablished measure of whole-body insulin sensitivity [16]. The insulin sensitivity index of Matsuda is defined as $10000 / \sqrt{ }$ [(FPG $\mathrm{x}$ fasting plasma insulin) $\mathrm{X}$ (mean glucose during OGTT $\mathrm{x}$ mean insulin during OGTT)] [16]. As a secondary measure of insulin sensitivity (largely hepatic), we also calculated the reciprocal of the homeostasis model assessment of insulin resistance (1/ HOMA-IR) [17]. HOMA-IR is calculated as the product of FPG and fasting plasma insulin divided by 22.5 [17]. Beta-cell function was assessed by the insulin secretion sensitivity index (ISSI-2), an OGTT-derived measure that is analogous to the disposition index obtained from the frequently sampled intravenous glucose tolerance test $[18,19]$. Glycaemia was assessed by the area under the glucose curve (AUC glucose) during the OGTT, calculated using the trapezoidal rule $[18,19]$. ISSI- 2 is defined as the product of 1) insulin secretion measured by the ratio of the AUC insulin to the AUC glucose and 2) insulin sensitivity measured by the insulin sensitivity index of Matsuda $[18,19]$. All these measures have been validated for use in pregnancy.

In UZ Leuven, $\mathrm{HbA}_{1 \mathrm{c}}$ was measured by reversedphase cation-exchange chromatography (ADAMS HA8160, Menarini Diagnostics Benelux, Zaventem, Belgium) and in OLV Aalst-Asse-Ninove hospital with a capillary zone electrophoresis on a Capillarys 2 Flex Piercing (Sebia). Hba1c is reported in compliance with the National Glycohemoglobin Standardization Program (NGSP). In Both centers plasma glucose was measured by an automated colorimetric-enzymatic method (hexokinase-glucose-6-phosphate-dehydrogenase, application 668) on a Hitachi/Roche-Modular P analyzer. Insulin was measured by the immunometric ECLIA (Roche Modular E170, Basel, Switserland).

\section{Statistical analyses}

Statistical analyses were performed using SPSS 22.0. Continuous variables were presented as mean and standard deviation if normally distributed and as median otherwise.

Categorical variables were presented as percentage. To compare variables between two groups independent samples $t$-tests were used for normally distributed continuous variables, Mann-Whitney's $U$-test for nonnormally distributed continuous variables and chisquared tests for categorical variables. A univariable analysis was done initially, and then clinical variables that were identified as most significantly associated with the need for insulin use were included in a multivariable logistic regression. Treatment with corticoids was a significant variable in the univariable analysis but this was not included in multivariable logistic regression since it could not be excluded that treatment with corticoids preceded the use of insulin in some patients. Multivariable logistic regression was also used to analyse the impact of possible confounders such as age, BMI, ethnicity, multi-parity, excessive weight gain and center on pregnancy outcomes and on the indices of insulin sensitivity and beta-cell function. Although the treatment protocol for GDM was similar in both centers, a center was also used as a variable to adjust for differences in population characteristics and potential differences in obstetrical management between both centers. A $p$-value of $<0.05$ (two-tailed) was considered significant.

\section{Results}

Over a 4 year period, 644 women were identified with GDM. After evaluation of the medical files, 43 files were not included in the analysis due to insufficient data (29) or because women took part in a study using the 'International Association of Diabetes and Pregnancy Study groups' (IADPSG) criteria for GDM (14), leaving a cohort of 601 women with GDM for analysis. Of the whole cohort 269 women $(44.8 \%)$ attended the university hospital and 332 women (55.2 \%) attended the nonuniversity hospital. The prevalence of GDM at the time of the study was $3.3 \%$ in the university center and $5.1 \%$ in the non-university center. Of the whole cohort, $29.7 \%$ had an abnormal fasting glycaemia on the OGTT, 
64.1\% had an abnormal 1-hour value, $90.5 \%$ had an abnormal 2-hour value and $68.7 \%$ had an abnormal 3hour value. In $47.4 \%$ of women the 3-hour value on the OGTT contributed to the diagnosis of GDM. Table 1 gives an overview of the general characteristics of the cohort. Of all women with GDM $24.5 \%$ were from an ethnic minority background (EMB): South Asian (25.3 \%), Northern-African (19.8 \%), Black African (18.4 \%) and Middle-East (13.0 \%). $24.1 \%$ (145) of women needed insulin during pregnancy. Of all women on insulin, $69.1 \%$ (92) received only short acting insulin, $2.3 \%$ (3) received only long-acting insulin and $28.6 \%$ (38) received both short -and long acting insulin. Of all women on short acting insulin, $57.1 \%$ (76) received short acting insulin at each meal. The most commonly used short acting insulins were the insulin analogues aspart or lispo (92.9\%) and the most commonly used long acting insulin was NPH insulin (90.2\%). The insulin was stopped after the delivery except in two women. The general characteristics were pretty similar between both centers. In particular, rates of insulin use were not significantly different between the university and nonuniversity center $(27.2 \%$ vs. $21.8 \%, p=0.291)$. Table 1 gives an overview of the similarities and differences between both centers.

Table 2 gives an overview of the differences in pregnancy outcomes of the whole cohort between the insulin- and diet-treated women GDM. Insulin did not prevent adverse outcomes, as women on insulin had higher rates of LGA ( $28.5 \%$ vs. $13.1 \%, p<0.0001)$ and more cesarean sections $(44.1 \%$ vs. $27.0 \%, p=0.001)$, remaining significant after adjustment for age, BMI, excessive weight gain, ethnicity, multi-parity and center.

Table 3 gives an overview of the differences in characteristics of the whole cohort between the insulin- and diet-treated women with GDM. Compared to diettreated women, women on insulin were more often from an EMB (33.3 \% vs. $21.6 \%, p=0.004)$, more often had a history of GDM (21.5\% vs. $10.4 \%, p=0.002)$, were more often multiparous (59.3 \% vs. $47.6 \%, p=0.044)$ and were diagnosed with GDM earlier in pregnancy. Women on insulin also had higher glycaemic values on the OGTT and more often 3 and 4 abnormal values with higher HbA1c levels at the time of the OGTT (Table 3). In the multivariable regression analysis fasting glycaemia at the time of the OGTT remained the only independent predictor for antenatal insulin requirement $(p<0.0001)$ (Table 3). Based on a receiver operating characteristics (ROC) curve for FPG with an AUC of 0.676, a FPG cutof $\geq 88.5 \mathrm{mg} / \mathrm{dl}(4.9 \mathrm{mmol} / \mathrm{l})$ had the best sensitivity and specificity combined of resp. $62.6 \%$ and $60.6 \%$ to predict insulin requirements. $62.8 \%$ of women who had a FPG $\geq 88.5 \mathrm{mg} / \mathrm{dl}(4.9 \mathrm{mmol} / \mathrm{l})$ on the OGTT required insulin treatment but with a low positive predictive value of $52.3 \%$.

Table 4 gives an overview of the differences in insulin sensitivity and beta-cell function between the insulinand diet-treated women with GDM attending the

Table 1 The general characteristics and the differences between both centers of the cohort of women with GDM

\begin{tabular}{|c|c|c|c|c|}
\hline & $\begin{array}{l}\text { General cohort } \\
N=-601\end{array}$ & $\begin{array}{l}\text { University hospital } \\
N=269(44.8 \%)\end{array}$ & $\begin{array}{l}\text { Non-University hospital } \\
N=332(55.2 \%)\end{array}$ & $p$-value \\
\hline Mean age (years) & $31.9 \pm 4.8$ & $32.0 \pm 4.8$ & $31.5 \pm 4.8$ & 0.028 \\
\hline$\%$ first degree relative with diabetes & $18.3 \%(109)$ & $14.9 \%(40)$ & $21.1 \%(69)$ & $<0.0001$ \\
\hline$\%$ second degree relative with diabetes & $21.8 \%(130)$ & $8.2 \%(22)$ & $33.0 \%(108)$ & $<0.0001$ \\
\hline$\%$ with a history of GDM & $13.1 \%(78)$ & $12.3 \%(33)$ & $13.8 \%(45)$ & 0.023 \\
\hline$\%$ overweight & $32.2 \%(158)$ & $34.2 \%(89)$ & $30.0 \%(69)$ & 0.317 \\
\hline$\%$ obese & $22.9 \%(112)$ & $22.3 \%(58)$ & $23.5 \%(54)$ & 0.758 \\
\hline$\%$ excessive weight gain & $19.7 \%(103)$ & $22.0 \%(55)$ & $17.5 \%(48)$ & 0.197 \\
\hline$\%$ EMB & $24.5 \%(146)$ & $37.2 \%(100)$ & $14.1 \%(46)$ & $<0.0001$ \\
\hline Fasting glycaemia at OGTT in $\mathrm{mg} / \mathrm{dl}(\mathrm{mmol} / \mathrm{l})$ & $90.0 \pm 13.4(5.0 \pm 0.7)$ & $93.6 \pm 15.6(5.5 \pm 0.9)$ & $87.3 \pm 10.8(4.8 \pm 0.6)$ & $<0.0001$ \\
\hline $\mathrm{HbA} 1 \mathrm{c}$, mean in $\%(\mathrm{mmol} / \mathrm{mol})$ & $5.3 \pm 0.5(34 \pm 6)$ & $5.4 \pm 0.5(36 \pm 6)$ & $5.1 \pm 0.4(32 \pm 5)$ & $<0.0001$ \\
\hline$\%$ Insulin use & $24.1 \%(145)$ & $27.2 \%(73)$ & $21.8 \%(72)$ & 0.291 \\
\hline$\%$ macrosomia & $8.7 \%(52)$ & $7.5 \%(20)$ & $9.7 \%(32)$ & 0.329 \\
\hline$\%$ LGA & $16.9 \%(101)$ & $16.8 \%(45)$ & $17.1 \%(56)$ & 0.927 \\
\hline$\%$ Preterm delivery & $13.0 \%(187)$ & $18.3 \%(49)$ & $8.8 \%(29)$ & $<0.0001$ \\
\hline$\%$ cesarean section & $31.2 \%(187)$ & $36.6 \%(98)$ & $26.96 \%(89)$ & 0.011 \\
\hline$\%$ shoulder dystocia & $1.2 \%(7)$ & $2.2 \%(6)$ & $0.3 \%(1)$ & 0.029 \\
\hline$\%$ admission NICU & $9.6 \%(57)$ & $16.4 \%(44)$ & $4.0 \%(13)$ & $<0.0001$ \\
\hline
\end{tabular}

GDM gestational diabetes, $E M B$ ethnic minority background, $O G T$ oral glucose tolerance test, $L G A$ large-for-gestational age infants, NICU neonatal intensive care unit, $\mathrm{P}$-values in bold are significant values 
Table 2 The differences in pregnancy outcomes between the insulin- and diet-treated women with GDM

\begin{tabular}{|c|c|c|c|c|}
\hline & Diet $N=456(75.9 \%)$ & Insulin N= 145 (24.1 \%) & $p$-value & Adjusted $p$-value \\
\hline$\%$ Gestational hypertension & $7.7 \%(35)$ & $4.2 \%(6)$ & 0.140 & \\
\hline$\%$ preeclampsia & $4.0 \%(18)$ & $7.6 \%(11)$ & 0.076 & \\
\hline$\%$ Preterm delivery & $12.8 \%(58)$ & $13.9 \%(20)$ & 0.743 & \\
\hline$\%$ cesarean section & $27.0 \%(122)$ & $44.1 \%(64)$ & $<0.0001$ & 0.001 \\
\hline Birth weight (g) & $3208.2 \pm 600.9$ & $3321.4 \pm 589.2$ & 0.049 & 0.144 \\
\hline$\%$ macrosomia & $7.3 \%(33)$ & $12.6 \%(18)$ & 0.049 & 0.226 \\
\hline$\%$ LGA & $13.1 \%(59)$ & $28.5 \%(41)$ & $<0.0001$ & $<0.0001$ \\
\hline$\%$ SGA & $11.3 \%(51)$ & $8.3 \%(12)$ & 0.309 & \\
\hline$\%$ shoulder dystocia & $1.1 \%(5)$ & $1.4 \%(2)$ & 0.788 & \\
\hline$\%$ low Apgar score & $2.2 \%(10)$ & $2.8 \%(4)$ & 0.702 & \\
\hline$\%$ admission NICU & $8.7 \%(39)$ & $12.5 \%(18)$ & 0.174 & \\
\hline
\end{tabular}

$g$ grams, LGA large-for-gestational age infants, SGA small-for-gestational age infants; low Apgar score: $<7$ at 5 min; NICU neonatal intensive care unit; The $p$-values are adjusted for age, BMl, excessive weight gain, ethnicity, multi-parity and center, P-values in bold are significant values

Table 3 The differences in characteristics between the insulin- and diet-treated women with GDM

\begin{tabular}{|c|c|c|c|c|}
\hline & Diet $N=456(75.9 \%)$ & Insulin $N=145(24.1 \%)$ & $p$-value & ${ }^{*}$ Adjusted $p$-value \\
\hline Age, mean (y) & $31.8 \pm 4.8$ & $32.5 \pm 4.7$ & 0.109 & \\
\hline Gestational age, mean (y) & $39.3 \pm 16.8$ & $38.0 \pm 1.6$ & 0.352 & \\
\hline Mean BMl $\left(\mathrm{Kg} / \mathrm{m}^{2}\right)$ at first prenatal visit & $26.8 \pm 12.9$ & $29.1 \pm 20.2$ & 0.149 & \\
\hline$\%$ overweight & $32.4 \%(121)$ & $31.6 \%(36)$ & 0.877 & \\
\hline$\%$ obese & $21.4 \%(80)$ & $27.2 \%(31)$ & 0.196 & \\
\hline$\%$ exessive weight gain & $18.5 \%(73)$ & $22.7 \%(29)$ & 0.306 & \\
\hline$\%$ EMB & $21.6 \%(97)$ & $33.3 \%(48)$ & 0.004 & 0.939 \\
\hline$\%$ first degree relative with diabetes & $16.7 \%(75)$ & $22.9 \%(33)$ & 0.107 & \\
\hline$\%$ second degree relative with diabetes & $23.1 \%(104)$ & $17.4 \%(25)$ & 0.107 & \\
\hline$\%$ history of GDM & $10.4 \%(47)$ & $21.5 \%(31)$ & 0.002 & 0.142 \\
\hline$\%$ multiparous & $47.6 \%(216)$ & $59.3 \%(86)$ & 0.044 & 0.998 \\
\hline$\%$ primigravida & $36.0 \%(163)$ & $23.4 \%(34)$ & 0.020 & 0.260 \\
\hline Week of GCT, mean & $25.4 \pm 3.3$ & $23.6 \pm 4.9$ & $<0.0001$ & 0.203 \\
\hline Value of GCT, mean in $\mathrm{mg} / \mathrm{dl}(\mathrm{mmol} / \mathrm{l})$ & $166.7 \pm 19.6(9.3 \pm 1.1)$ & $179.0 \pm 40.0(9.9 \pm 2.2)$ & $<0.0001$ & 0.304 \\
\hline Week of GDM diagnosis mean & $27.1 \pm 3.7$ & $25.3 \pm 4.9$ & $<0.0001$ & 0.278 \\
\hline Fasting glycaemia at OGTT in $\mathrm{mg} / \mathrm{dl}(\mathrm{mmol} / \mathrm{l})$ & $87.7 \pm 10.3(4.9 \pm 0.6)$ & $97.6 \pm 18.8(5.4 \pm 1.0)$ & $<0.0001$ & $<0.0001$ \\
\hline 1-hour glycaemia at OGTT in mg/dl (mmol/l) & $184.5 \pm 25.8(10.2 \pm 1.4)$ & $194.7 \pm 30.1(10.8 \pm 1.7)$ & $<0.0001$ & 0.417 \\
\hline 2-hour glycaemia at OGTT in mg/dl (mmol/l) & $175.0 \pm 22.8(9.7 \pm 1.3)$ & $185.2 \pm 28.5(10.3 \pm 1.6)$ & $<0.0001$ & 0.342 \\
\hline 3-hour glycaemia at OGTT in mg/dl (mmol/l) & $145.4 \pm 27.6(8.1 \pm 1.5)$ & $152.7 \pm 33.4(8.5 \pm 1.8)$ & 0.013 & 0.238 \\
\hline$\% \geq 3$ abnormal values on the OGTT & $37.8 \%(161)$ & $58.1 \%(75)$ & $<0.0001$ & 0.915 \\
\hline$\% \geq 4$ abnormal values at OGTT & $7.7 \%(33)$ & $24.8 \%(32)$ & $<0.0001$ & 0.756 \\
\hline $\mathrm{HbA} 1 \mathrm{c}$, mean in \% $(\mathrm{mmol} / \mathrm{mol})$ & $5.2 \pm 0.5(33 \pm 6)$ & $5.5 \pm 0.6(37 \pm 6)$ & $<0.0001$ & 0.496 \\
\hline$\%$ treatment with corticoïds & $2.4 \%(11)$ & $11.0 \%(16)$ & $<0.0001$ & \\
\hline
\end{tabular}

$Y$ years, $B M I$ body mass index, EMB ethnic minority background, GCT glucose challenge test, OGTT oral glucose tolerance test, GDM gestational diabetes *Adjusted $p$-value: Clinical variables that were identified as most significantly associated with the need for insulin use were included in the multivariable logistic regression, P-values in bold are significant values 
Table 4 The differences in insulin sensitivity and beta-cell function between the insulin- and diet-treated women with GDM from the university hospital

\begin{tabular}{lcccc}
\hline & Diet $N=196(73.0 \%)$ & Insulin $N=73(27.0 \%)$ & $P$ value & Adjusted $p$ value \\
\hline ISSI-2 index mean & $1.7 \pm 0.5$ & $1.3 \pm 0.5$ & $<\mathbf{0 . 0 0 0 1}$ & $\mathbf{0 . 0 0 0 1}$ \\
Matsuda index median & $2.9(1.9-3.7)$ & $2.3(1.4-3.3)$ & $\mathbf{0 . 0 1 9}$ & 0.206 \\
1/HOMA-IR median & $0.02(0.01-0.03)$ & $0.01(0.01-0.02)$ & $<\mathbf{0 . 0 0 0 1}$ & $\mathbf{0 . 0 2 7}$ \\
\hline
\end{tabular}

GDM: gestational diabetes; ISSI-2: insulin secretion sensitivity index during pregnancy; Matsuda: insulin sensitivity index of Matsuda during pregnancy; 1/HOMA-IR: the reciprocal of the homeostasis model assessment of insulin resistance during pregnancy. The $p$-values are adjusted for age, BMl, excessive weight gain, ethnicity and multi-parity, P-values in bold are significant values

university hospital. In women attending the university hospital, ISSI-2 $(1.3 \pm 0.5$ vs. $1.7 \pm 0.5, p<0.0001)$ and $1 /$ HOMA-IR [0.01 (0.001-0.002) vs. 0.02 (0.01-0.03), $p=$ 0.027] were significantly lower in women on insulin, remaining significant after adjustment for age, BMI, excessive weight gain, ethnicity and multi-parity.

\section{Discussion}

The insulin requirement for the treatment of GDM varies according to the population studied and which screening strategy and diagnostic criteria are used for GDM. Most studies show insulin use in GDM between $10-30 \%$, in line with the insulin need in our study of $24.1 \%$ [20-22]. Insulin did not prevent adverse outcomes in our study, as women on insulin had higher rates of LGA $(28.5 \%)$ and more cesarean sections (44.1\%) compared to diet-treated women (resp. $13.1 \%$, $p<0.0001$ and $27.0 \%, p=0.001$ ), remaining significant after adjustment for BMI, excessive weight gain, ethnicity, age, multi-parity and center. These data show that especially in women on insulin, rates of LGA and cesarean sections remain much higher compared to the LGA and cesarean rates in pregnant women without GDM of resp. $9.0 \%$ and $23.3 \%$ in our population, as was shown previously by our research group [23]. Controlling hyperglycaemia in pregnancy is certainly not the only essential factor to decrease the problem of LGA newborns. The HAPO study has shown that both maternal GDM and obesity are independently associated with adverse pregnancy outcomes and that the combination of obesity and GDM shows a greater risk of these adverse pregnancy outcomes than either obesity or GDM alone [24]. Gestational weight gain is also a known independent risk factor for accelerated fetal growth [25]. BMI and excessive weight gain were however not different between the two groups in our study but of all women with GDM $32.2 \%$ were overweight and $22.9 \%$ were obese at the first prenatal visit. There is clearly a need for better preconception assessment and counseling for overweight and obese women with the aim to lose weight before pregnancy and also to limit weight gain in pregnancy. In our study oral anti-diabetes drugs were not used during pregnancy. Insulin has been the treatment of choice when lifestyle measures do not maintain glycemic control during pregnancy. The long acting insulins NPH and detemir and the short acting insulins human regular and the insulin analogues lispro and aspart have all been proven to be safe for use during pregnancy [7]. However, insulin is associated with an increased risk for hypoglycaemia and weight gain, which might be a hurdle to reach an optimal glycaemic control and contribute to the increased rates of adverse pregnancy outcomes seen in women with GDM on insulin. Some studies have suggested that metformin may be a safe and acceptable alternative for the treatment of GDM with less maternal weight gain compared to insulin and with no increase in congenital anomalies, despite it crossing the placenta $[8,26,27]$. However there is a paucity of long-term follow up data on children exposed to oral agents in utero. More research is therefore necessary to evaluate whether the addition of metformin to insulin can improve pregnancy outcomes in women with GDM and whether this is also safe on the long term.

Our study also shows that women with GDM on insulin had a more adverse metabolic risk profile compared to diet-treated women with GDM with an earlier diagnosis of GDM, higher glucose values on the OGTT and more often $>2$ abnormal values on the OGTT. Women on insulin were also more often from an EMB, more often multiparous and more often had a history of GDM. However only the fasting glycaemia at the time of the OGTT was an independent predictor for antenatal insulin requirement in the regression analysis in our population. Other studies have shown independent predictors for antenatal insulin requirement to be a positive family history of diabetes, multiple abnormal values on the OGTT, the BMI, the time of diagnosis, the fasting glucose on the OGTT and HbA1c at the diagnosis of GDM [20-22]. The large variation seen in predictors between the different studies is probably related to the differences in the ethnic origin of the populations studied, the differences in sample size and the different screening strategies used for GDM. Several studies have indicated fasting glucose during the OGTT as a potent predictor of antenatal insulin treatment in GDM, in accordance with our finding $[22,28,29]$. However, depending on the methodology of the study, on the target of glucose levels used or ethnic differences, different cut-off values of 
fasting glucose varying from $87 \mathrm{mg} / \mathrm{dl}(4.8 \mathrm{mmol} / \mathrm{l})$ to $105 \mathrm{mg} / \mathrm{dl}(5.8 \mathrm{mmol} / \mathrm{l})$ have been demonstrated to predict the need for insulin [22, 28, 29]. In our population a FPG cut-off level $\geq 88.5 \mathrm{mg} / \mathrm{dl}(4.9 \mathrm{mmol} / \mathrm{l})$ had the best sensitivity and specificity rates but with a low positive predictive value. This FPG cut-off is lower than the general recommended FPG target for the treatment of GDM of $<95 \mathrm{mg} / \mathrm{dl}(5.3 \mathrm{mmol} / \mathrm{l})$ and is also closer to the FPG cut-off proposed by the IADPSG for the diagnosis of GDM compared to the Carpenter \& Coustan criteria we used. This might suggest that a lower FPG target for the treatment of GDM might be indicated but there is a need for large randomized intervention trials evaluating the benefit of lower glycaemic targets for the treatment of GDM on pregnancy outcomes.

Our data also show a reduced insulin sensitivity and impaired beta-cell function in women on insulin, which remained significant after adjustment for confounders such as BMI, age, ethnicity, and excessive weight gain. It has long been thought that the insulin resistance provided a short-term challenge to the beta-cells, with GDM arising in those women whose beta-cells were unable to meet this challenge. Several studies have shown that the defect in beta-cell compensation that characterizes GDM is chronic and probably not just acquired during pregnancy. Shortly after delivery the insulin resistance is generally restored to the pre-pregnancy level but often the chronic beta-cell dysfunction persists $[30,31]$. We have previously shown in our population that $39.1 \%$ of women with a recent history of GDM, had glucose intolerance based on the OGTT three months postpartum and that these women also had a persistent impaired beta-cell function and lower insulin sensitivity postpartum [32].

In our cohort, less than one third of women had an abnormal fasting glycaemia on the OGTT while the 2hour and 3-hour glycaemia values were most frequently abnormal. However, in contrast to the FPG, the 2-and 3hour glycaemia were not anymore significantly associated with the use of insulin in the multivariable logistic regression. The use of a 2-hour 75 g OGTT with the Carpenter \& Coustan criteria for the diagnosis of GDM was accepted as an alternative by the previous ADA recommendations, but this is clearly less validated than the use of the 3-hour $100 \mathrm{~g}$ OGTT [1]. If a 2-hour $75 \mathrm{~g}$ OGTT would be used in our population with the Carpenter \& Coustan criteria for GDM, the prevalence of GDM would decrease importantly since the 3-hour value contributed to the diagnosis of GDM in nearly half of all women with GDM.

Strengths of the study are the detailed characterization of a large cohort of women with GDM using a good database. Variables that were identified as most significantly associated with the need for insulin use were included in a multivariable logistic regression. Pregnancy outcomes and measures of insulin sensitivity and beta-cell function were adjusted for multiple confounders. A limit of the study is the retrospective nature of the analysis and the fact that insulin values were only available from women attending the university hospital.

\section{Conclusions}

Compared to diet-treated women with GDM, women treated with insulin have a higher metabolic risk profile, impaired beta-cell function and lower insulin sensitivity. Moreover, insulin did not prevent adverse outcomes, as rates of LGA and cesarean sections were still higher in insulin-treated women. Women with GDM needing insulin remain a high risk population and more research is necessary to improve outcomes in this group.

Competing interests

The authors declare that they have no competing interests.

Authors' contributions

$\mathrm{KB}, \mathrm{KR}, \mathrm{FN}, \mathrm{ND}, \mathrm{PVC}$ and CM have made substantial contributions to the conception of the study and have been involved in drafting the manuscript. $\mathrm{KB}$ and $\mathrm{KR}$ have collected the data. KB, KR, FN, ND, PVC, JV, RD and CM have been involved in revising it critically for important intellectual content. All authors have given final approval of the version to be published.

\section{Acknowledgements}

KB is the recipient of a Clinical Doctoral Scholarship of 'FWO Vlaanderen' and $\mathrm{RD}$ is the recipient of a 'Fundamenteel Klinisch Navorserschap FWO Vlaanderen'.

\section{Author details}

'Department of Endocrinology, UZ Gasthuisberg, KU Leuven, Herestraat 49, 3000 Leuven, Belgium. ²Department of Endocrinology, OLV ziekenhuis Aalst-Asse-Ninove, Moorselbaan 164, 9300 Aalst, Belgium. ${ }^{3}$ Department of Obstetrics and Gynecology, OLV ziekenhuis Aalst-Asse-Ninove, Moorselbaan 164, 9300 Aalst, Belgium. ${ }^{4}$ Department of Obstetrics and Gynecology, UZ Gasthuisberg, KU Leuven, Herestraat 49, 3000 Leuven, Belgium.

Received: 29 May 2015 Accepted: 15 October 2015

Published online: 23 October 2015

\section{References}

1. American Diabetes Association. Diagnosis and classification of diabetes mellitus. Diabetes Care. 2009;32:S62-7.

2. Study HAPO, Cooperative Research Group, Metzger BE, Lowe LP, Dyer AR, Trimble ER, et al. Hyperglycemia and adverse pregnancy outcomes. N Engl J Med. 2008;358:1991-2002.

3. Gilmartin AB, Ural SH, Repke JT. Gestational diabetes mellitus. Rev Obstet Gynecol. 2008;1:129-34.

4. Bellamy L, Casas JP, Hingorani AD, Williams D. Type 2 diabetes mellitus after gestational diabetes: a systematic review and meta-analysis. Lancet. 2009:373:1773-9.

5. Crowther CA, Hiller JE, Moss JR, McPhee AJ, Jeffries W, Robinson JS. Australian Carbohydrate Intolerance study in Pregnancy Women (ACHOIS) Trial Group. Effect of treatment of gestational diabetes mellitus on pregnancy outcomes. N Engl J Med. 2005;352:2477-86.

6. Landon MB, Spong CY, Thom E, Carpenter M, Ramin SM, Casey B, et al. A multicenter, randomized trial of treatment for mild gestational diabetes. $\mathrm{N}$ Engl J Med. 2009;361:1339-48.

7. American Diabetes Association. Standards of Medical Care in diabetes-2014. Diabetes Care. 2014;37:S14-80.

8. Rowan JA, Hague WM, Gao W, Battin MR, Moore MP, MiG Trial Investigators. Metformin versus insulin for the treatment of gestational diabetes. N Engl J Med. 2008;358:2003-15. 
9. Zeng YC, Li MJ, Chen Y, Jiang L, Wang SM, Mo XL, et al. The use of glyburide in the management of gestational diabetes mellitus: a metaanalysis. Adv Med Sci. 2014;59:95-101.

10. Myngheer N, Allegaert K, Hattersley A, McDonald T, Kramer H, Ashcroft FM, et al. Fetal macrosomia with transplacental transfer of sulfonylurea in a mother with KCNJ11-related neonatal diabetes. Diabetes Care. 2014;37:3333-5.

11. International Diabetes Federation, Diabetes e-Atlas, 6th edn, Brussels. http://www.idf.org/sites/default/files/EN_6E_Atlas_Full_0.pdf (2013). Accessed 13 March 2015

12. Http://statbel.fgov.be/nl/statistieken/cijfers/bevolking/structuur. Accessed 20 December 2012

13. Benhalima K, Van Crombrugge P, Devlieger R, Verhaeghe J, Verhaegen $A$, De Catte $L$, et al. Screening for pregestational and gestational diabetes in pregnancy: a survey of obstetrical centers in the northern part of Belgium. Diabetology and Metabolic Syndrome. 2013;5:66. doi:10.1186/1758-5996-5-66.

14. Metzger BE, Buchanan TA, Coustan DR, de Leiva A, Dunger DB, Hadden $\mathrm{DR}$, et al. Summary and recommendations of the Fifth International Workshop-Conference on Gestational Diabetes Mellitus. Diabetes Care. 2007:30 suppl 2:\$251-60.

15. Institute of Medicine (US) and National Research Council (US) Committee to Reexamine IOM Pregnancy Weight Guidelines. Weight Gain During Pregnancy: Reexamining the Guidelines. In: Rasmussen KM, Yaktine AL, editors. National Academies Press (US). Washington: The National Academies Collection: Reports funded by National Institutes of Health; 2009.

16. Matsuda M, Defronzo RA. Insulin sensitivity indices obtained from oral glucose tolerance testing. Comparison with the euglycemic insulin clamp. Diabetes Care. 1999;22:1462-70.

17. Matthews DR, Hosker JP, Rudenski AS, Naylor BA, Treacher DF, Turner RC. Homeostasis model assessment: insulin resistance and beta-cell function from fasting plasma glucose and insulin concentrations in man. Diabetologia. 1985;28:412-9.

18. Kirwan JP, Huston-Presley L, Kalhan SC, Catalano PM. Clinically useful estimates of insulin sensitivity during pregnancy: validation studies in women with normal glucose tolerance and gestational diabetes. Diabetes Care. 2001;24:1602-7.

19. Retnakaran R, Qi Y, Goran MI, Hamilton JK. Evaluation of proposed oral disposition index measures in relation to the actual disposition index. Diabet Med. 2009:26:1198-203.

20. Mitra S, Nayak PK, Sahoo J, Mathew A, Padma A, Kamalanathan S, et al Predictors for antenatal insulin requirements in gestational diabetes. Gynecol Endocrinol. 2014;30:565-8.

21. Wong W, Jalaludin B. Gestational diabetes mellitus: who requires insulin therapy? Aust NZ J Obstet Gynaecol. 2011;51:432-6.

22. Bakiner O, Bozkirli E, Ozsahin K, Sariturk C, Ertorer E. Risk factors that can predict antenatal insulin need in gestational diabetes. J Clin Med Res. 2013;5:381-8.

23. Benhalima K, Hanssens M, Devlieger R, Verhaeghe J, Mathieu C. Analysis of pregnancy outcomes using the new IADPSG recommendation compared with the Carpenter and Coustan criteria in an area with a low prevalence of gestational diabetes. Int J Endocrinology. 2013. doi:10.1155/2013/248.121.

24. Catalano PM, McIntyre HD, Cruickshank JK, McCance DR, Dyer AR, Metzger $\mathrm{BE}$, et al. The Hyperglycemia and adverse pregnancy outcome study. Associations of GDM and obesity with pregnancy outcomes. Diabetes Care. 2012:35:780-6.

25. Ludwig DS, Currie J. The association between pregnancy weight gain and birthweight: a within-family comparison. Lancet. 2010;376:984-90.

26. Gui J, Liu Q, Feng L. Metformin vs insulin in the management of gestational diabetes: a meta-analysis. Plos One. 2013;8:e64585-5.

27. Balsells M, Garcia-Patterson A, Sola I, Roque M, Gich I, Corcoy R. Glibenclamide, metformin, and insulin for the treatment of gestational diabetes: a systematic review and meta-analysis. BMJ. 2015. doi:10.1136/ nmj.h102.

28. Juutinen J, Hartikainen AL, Bloigu R, Tapanainen JS. A retrospective study on 435 women with gestational diabetes: fasting plasma glucose is not sensitive enough for screening but predicts a need for insulin treatment. Diabetes Care. 2000;23:1858-9.

29. Akinci B, Caltik A, Yener S, Yesil S. Is fasting glucose level during oral glucose tolerance test an indicator of the insulin need in gestational diabetes ? Diabetes Res Clin Pract. 2008;82:219-25.
30. Buchanan A, Xiang AH. Gestational diabetes mellitus. J Clin Invest. 2005;115:485-91.

31. Buchanan TA. Pancreatic B-Cell Defects in Gestational Diabetes: Implications for the Pathogenesis and Prevention of Type 2 Diabetes. J Clin Endocrinol Metab. 2001;86:989-93.

32. Benhalima K, Leuridan L, Calewaert P, Devlieger R, Verhaeghe J, Mathieu C. Glucose intolerance after a recent history of gestational diabetes. Int J Endocrinology. 2014. doi:10.1155/2014/727652.

\section{Submit your next manuscript to BioMed Central and take full advantage of:}

- Convenient online submission

- Thorough peer review

- No space constraints or color figure charges

- Immediate publication on acceptance

- Inclusion in PubMed, CAS, Scopus and Google Scholar

- Research which is freely available for redistribution

Submit your manuscript at www.biomedcentral.com/submit 